\title{
MeetingReport
}

\section{The 6th Meeting of the International Union of Microbeam Analysis Societies}

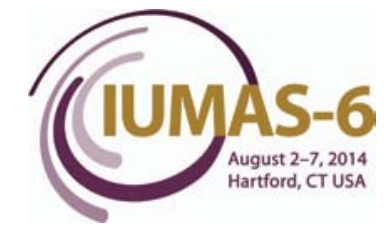

\author{
Edward P. Vicenzi, IUMAS-6 Chair
}

Museum Conservation Institute, Smithsonian Institution, 4210 Silver Hill Road, Suitland, MD 20746

vicenzie@si.edu

The $6^{\text {th }}$ meeting of the International Union of Microbeam Analysis Societies (IUMAS-6) was hosted by the Microanalysis Society (MAS) last year from August 2-7 in conjunction with Microscopy \& Microanalysis 2014 (M\&M 2014) in Hartford, CT. The meeting was attended by 221 participants from 19 nations and was highly successful, owing to the active participation of all IUMAS member societies from across the globe representing Australia, Brazil, Canada, China, Europe, Japan, Korea, and the USA. As an additional testament of their support, IUMAS member societies co-funded 16 Early Career Scholars to attend the events in Hartford. IUMAS- 6 began two days in advance of M\&M 2014 symposia, including social events where old friends reconnected and new connections were made, at the Saturday evening reception and lunch gatherings.

The weekend scientific program featured a full-day plenary session of microanalysis presentations. The president of Worcester Polytechnic Institute, Laurie Leshin, gave a fascinating keynote lecture, "My Lab is on Mars: Geochemical Adventures with the Mars Curiosity Rover." Prof. Leshin has been involved with NASA's Mars Science Laboratory mission for over a decade and served on a team that defined the scientific objectives for the mission. Her descriptions of the package of instruments on the Mars Curiosity Rover and the discoveries made based on new data obtained from rover instrumentation, together with her infectious enthusiasm for space exploration, made for a riveting presentation (Figure 1). Leaders from a variety of microanalysis disciplines then outlined state-ofthe-art methodologies and emerging techniques and applications in their areas of expertise, including: Colin MacRae (Australia) on the future multi-spectral electron microprobe, Paul Kotula (USA) on advances in acquisition of hyperspectral images, Masashi Watanabe (USA) on atomic resolution X-ray analysis in aberration-corrected scanning transmission electron microscopes, Chan-Gyung Park (Korea) on impacts of atom probe tomography on electronic and photonic device technology, Gianluigi Botton (Canada) on advances in electron energy-loss spectroscopy with high spatial and energy resolution, Birgit Hagenhoff (Germany) on mass spectrometry of surfaces using ion beams for molecular mapping of (bio)polymers, and Peta Clode (Australia) on elemental analysis of cells and tissues. Additionally, David B. Williams honored H.G.J. Moseley 100 years after his seminal discoveries in X-ray spectroscopy, in his own unique and humorous fashion. Finally, Joe Goldstein and Charles Lyman crafted a presentation remembering the significant contributions to MAS made by co-founder Robert E. Ogilvie.

Attendees had the difficult decision of selecting from 12 half-day workshops covering a wide range of areas of microanalysis and microscopy including the following: Advanced Electron Probe Microanalysis, Atom Probe Tomography, Electron

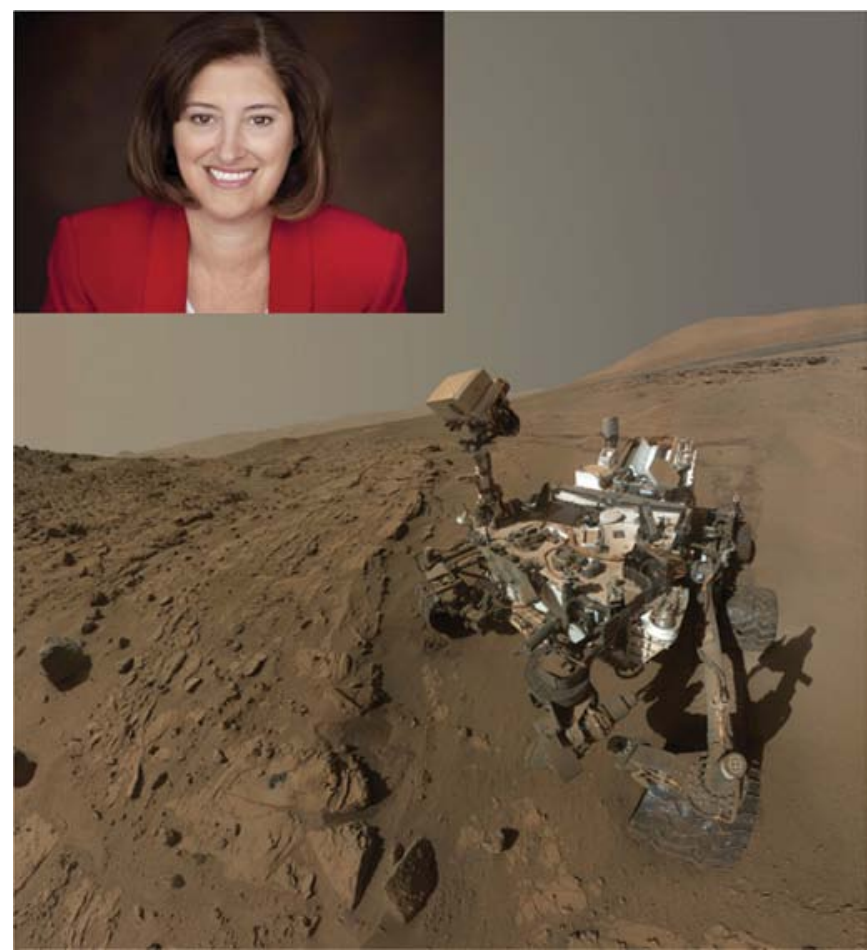

Figure 1: NASA's Curiosity Mars Rover used the camera at the end of its arm in April and May 2014 to take dozens of component images combined into this self-portrait where the rover drilled into a sandstone target called Windjana. Image provided courtesy of NASA/JPL-Caltech/MSSS. Inset: IUMAS- 6 keynote speaker Prof. Laurie Leshin. Image provided courtesy of Worcester Polytechnic Institute.

Backscatter Diffraction, Electron and X-ray Spectroscopies in the TEM/STEM, He/Ne Ion Microscopy and Microanalysis, Quantitative X-ray Microanalysis by XEDS, Trace Element Microanalysis by Laser Ablation ICP-MS, Focused Ion Beam Microscopy and Microanalysis, Microscopy and Microanalysis in the Variable Pressure SEM, Scanning Probe Microscopy, Spectral Imaging and Analysis, and X-ray Spectral Processing and Simulation.

A particularly memorable MAS/IUMAS-6 social event was held at The Society Room of Hartford. Once a nineteenth-century bank, the setting was elegant, the food was abundant, and the drinks flowed with conversations.

We are glad that blending IUMAS-6 with M\&M 2014 worked out so well and provided high-quality science with an engaging social atmosphere for our international colleagues. Now we must wait three years for IUMAS-7 as it moves to Europe, specifically in Konstanz, Germany. We hope to see you there in 2017! 


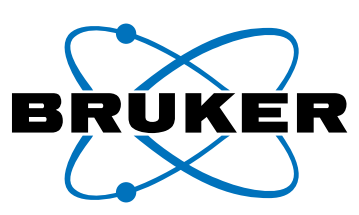

\section{5-in-1 fantasy: Giralope.}

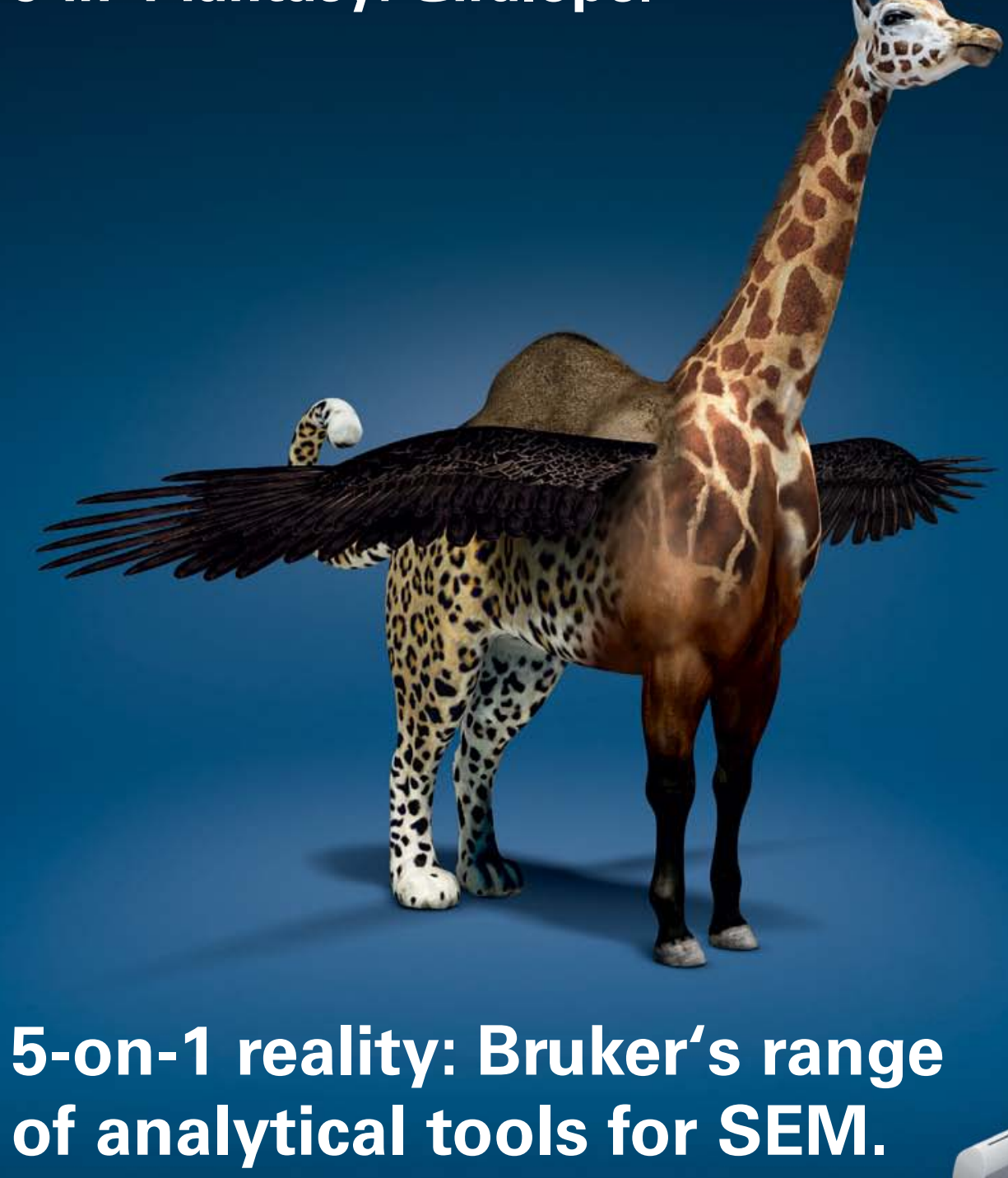

EDS, EBSD, WDS, Micro-XRF and Micro-CT - Bruker is the world's only manufacturer to offer five analysis methods for SEM. Plus, our new ESPRIT 2.0 software not only controls our QUANTAX EDS and QUANTAX EBSD but also, via its functional interface, our innovative new XSense WD spectrometer and XTrace micro-spot X-ray source. And because we know what you expect of us, we are already thinking about our next innovation. Someone has to be first.

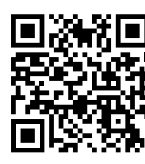

www.bruker-5on1.com

Innovation with Integrity 